\title{
Influence of Different Processing Methods on Aflatoxin Level in Ogi Slurry Produced from Millet (Pennisetum typhoideum)
}

\author{
Jeff-Agboola Yemisi Adefunke', Oluwatuyi Olatunji Joseph ${ }^{2}$, Onifade Anthony Kayode², \\ Adeleke Bartholomew Saanu ${ }^{2, *}$ \\ ${ }^{1}$ Department of Biological Sciences, University of Medical Sciences, Ondo City, Nigeria \\ ${ }^{2}$ Department of Microbiology, Federal University of Technology, Akure, Nigeria
}

Email address:

microbade@yahoo.com (A. B. Saanu)

${ }^{*}$ Corresponding author

\section{To cite this article:}

Jeff-Agboola Yemisi Adefunke, Oluwatuyi Olatunji Joseph, Onifade Anthony Kayode, Adeleke Bartholomew Saanu. Influence of Different Processing Methods on Aflatoxin Level in Ogi Slurry produced from Millet (Pennisetum typhoideum). American Journal of Bioscience and Bioengineering. Vol. 5, No. 4, 2017, pp. 83-87. doi: 10.11648/j.bio.20170504.11

Received: August 27, 2017; Accepted: September 9, 2017; Published: October 16, 2017

\begin{abstract}
The global shortage of cereal foods arising from improper processing and preservation methods adopted in some of our industries could be the sources of contamination of various food products which could lead to devastating health disorder. From this study, millet grains were subjected to different processing methods such as fermentation, alkaline boiling, oven drying and sun drying. The microorganisms associated with the processed samples were isolated and identified using standard microbiological and biochemical methods. The extraction, detection and quantification of aflatoxin from ogi slurry were quantified using thin layer chromatography. The sample fermented with ethanol and water showed higher fungal count $37.33 \mathrm{cfu} / \mathrm{ml}$ while the sample fermented in sodium hypochloride shown no growth of Aspergillus flavus with fermentation time at initial inoculation. The milled fermented oven dry sample showed higher colony counts $14.50 \mathrm{cfu} / \mathrm{g}$ when compared to milled sun-dry and alkaline boiling fermented samples. The aflatoxin level of the ogi slurry ranged from $0.00 \mathrm{ppb}$ to $0.02 \mathrm{ppb}$. Samples fermented with water and ethanol showed high effect in removal of aflatoxin B and G produced by toxigenic Aspergillus flavus while the alkaline boiling showed less effect on aflatoxin $\mathrm{B}_{1}$ and $\mathrm{B}_{2}$. Aflatoxin $\mathrm{G}_{1}$ and $\mathrm{G}_{2}$ were completely removed/destroyed from the sample fermented with ordinary water with aflatoxin level $0.00 \mathrm{ppb}$. The sample subjected to oven dry and sun-dry showed complete removal/reduction in aflatoxin $B_{1}$ and $\mathrm{G}_{1}$. The reduction in aflatoxin level of ogi slurry produced from millet using different processing methods showed its permissible level below the standard as recommended by National Agency for Food Drug Administration and Control (NAFDAC) and European Union which could be promising prior to this methods in controlling the level of contaminant in our food products for human use.
\end{abstract}

Keywords: Aflatoxin, Aspergillus flavus, Cereals, Food Contamination, Ogi Slurry

\section{Introduction}

Contamination of food products after post-harvesting processing has been the major concern in food industries. This occurrence devalue the wholesomeness of products thereby leading to shortage and reduction in its economic value. The contamination of food might arise from the improper handling of food or during food processing. Food contamination usually results from human, animal, rodents, insect and microorganisms. Microbial food contamination on cereal products occurs due to suitable environmental condition such as humidity, temperature, $\mathrm{pH}$, moisture content of where they are stored or preserved. Microbial food contamination majorly pose health risk on consumption of such food substance infested with toxic substance called mycotoxin. Mycotoxin are toxin produced from fungi which contaminate both human and animal diets before harvest and during storage thereby causing great economic loss in both the livestock industry and aquaculture [1]. The three major 
genera of fungi that produce mycotoxins are, Aspergillus, Fusarium and $P$ enicillium [2]. Though not all mycotoxins are toxic, mostly the mycotoxin produced by Penicilliun notatum but the toxigenic Aflatoxins strain from Aspergillus flavus, Fusarium spp on humans results in carcinogenic cellular disruption, cytotoxic necrosis, lose membrane integrity, immunosuppressant, nephrotoxic, neurotoxic and teratogenic [3].

There are different types of aflatoxins produced in nature, Aflatoxin $B_{1}, B_{2}, G_{1}, G_{2}$ with derivatives $M_{1}$ and $M_{2}$ [4]. The most common one is Aflatoxins $\mathrm{B}_{1}$ which are majorly produced from Aspergillus flavus and Aspergillus parasiticus [5]. Aflatoxins $\mathrm{G}_{1}$ and $\mathrm{G}_{2}$ are produced exclusively by Aspergillus parasiticus. The presence of Aspergillus spp in food products does not always indicate harmful levels of aflatoxin but with significant risk in consumption of such product [6].

Aflatoxins $\mathrm{M}_{1}$ and $\mathrm{M}_{2}$ usually contaminate milk obtained from cows that were fed on moldy grains. These compounds are products of a conversion process in the animal's liver. However, aflatoxin $\mathrm{M}_{1}$ can be found in the fermentation broth of Aspergillus parasiticus. Ingestion of contaminated food by aflatoxins might result in acute toxicity [7]. The infestation of mycotoxins producing fungi could be ameliorated using different processing techniques such as heat treatment, fermentation and chemical treatment of some of the food and food products that are prone to aflatoxin contamination. Therefore, decontamination of our food products by different processes methods from aflatoxin infestation could reduce its toxicity with a view of making safe without mutation through different processing techniques mostly is cereal grains.

\section{Materials and Methods}

\subsection{Fungi Isolate}

The toxigenic strains of Aspergillus flavus was collected from the Microbiology unit of Food and Science Technology Department, Federal University of Technology, Akure. The toxigenic strains of Aspergillus flavus was maintained by inoculation onto a fresh prepared potato dextrose agar. Sterile plunger was used to bore about ten portions of the pure isolate into a vial containing sterile water and two drops of tween 20, labeled and stored in refrigerator until further use.

\subsection{Collection of Samples}

Seeds of pearl (African) millet were purchased from Oja Oba market, Akure, Ondo State, Nigeria inside a sterile sealable bags and then transported to the Microbiology laboratory for analyses.

\subsection{Preparation of Spore Suspension}

The freshly prepared potato dextrose agar was inoculated with toxigenic strain of Aspergillus flavus then allowed to sporulate at $28 \pm 2^{\circ} \mathrm{C}$ for five days. The spore suspension was harvested and poured into sterile McCartney bottles.

\subsection{Preparation of Samples}

The weighed $200 \mathrm{~g}$ of the millet were inoculated with 5.25 $\times 10^{6} \mathrm{cfu} / \mathrm{ml}$ spores of aflatoxigenic strain of Aspergillus flavus, steep in water containing ethanol and hypochloride in ratio 1:20 and then ferment for 96 hours. The fermented inoculated millet grains were milled-blended and sieved. The resultant $O g i$ slurry was divided into two portion $50 \mathrm{~g}$ each. The first portion was boiled in water for 20 minutes. The second portion was added with $0.1 \mathrm{M} \mathrm{NaOH}$ before boiling (alkaline boiling). About $50.0 \mathrm{~g}$ portion of $\mathrm{Ogi}$ slurry was placed in an oven at $105^{\circ} \mathrm{C}$ for 60 minute and then sun dried for 90 minutes.

\subsection{Determination of Total Viable Count of Aspergillus Flavus}

Serial dilution and pour plate methods were used for determining the total viable counts of toxigenic strain of Aspergillus flavus in the samples using appropriate mycological medium. For the isolation, $1.0 \mathrm{~g}$ of the sample was weighed and macerated, dispensed into $9 \mathrm{ml}$ of sterile distilled water and then serially diluted up to $10^{-3}$ dilution factor. One milliliter from the diluent was pipette into a sterile Petri dish containing $0.02 \mathrm{ml}$ of lactic acid, then pour plate with already sterilized molten agar [8].

\subsection{Extraction of Aflatoxin from the Ogi Slurry}

Extraction of Aflatoxin from $O g i$ slurry was determined according to modified method of $[9,10]$. Fifty grams $(50 \mathrm{~g})$ of Ogi slurry were put into $500 \mathrm{ml}$ conical flask, $250 \mathrm{ml}$ of methanol:water $(60: 40 \mathrm{v} / \mathrm{v})$ was added. The flask was placed in a mechanical shaker for 30 minutes. The solution was allowed to settle, filtered using Whatman paper No. 1. One hundred and twenty milliliter $(120 \mathrm{ml})$ of the filtrate was taken into a $250 \mathrm{ml}$ separating funnel, containing $30 \mathrm{ml}$ of saturated sodium chloride solution and $50 \mathrm{ml}$ hexane. The flask was shaken vigorously for 2 minutes and the solutions were allowed to separate. The lower methanol layer was collected in another $250 \mathrm{ml}$ separating funnel and $50 \mathrm{ml}$ chloroform was added. It was then shaken vigorously, giving frequent vents. The chloroform layer was drained into a conical flask containing $5.0 \mathrm{~g}$ of cupric carbonate. It was shaken and cupric carbonate was allowed to settle. This was filter through Whatman filter paper No. 42 having a bed of anhydrous sodium sulphate. The chloroform extract was then collected in a beaker.

\subsection{Detection of Aflatoxin in the Ogi Slurry}

Cupric carbonate was washed with $25 \mathrm{ml}$ chloroform, filter through sodium sulphate bed. The extracts were combined and evaporate in a water bath. The residue was reconstituted by dissolving in $1 \mathrm{ml}$ of chloroform and transferred into a screw cap vial. One milliliter $(1.0 \mathrm{ml})$ chloroform and $0.2 \mathrm{ml}$ of the reconstituted extract were spotted on a pre-coated $20 \times$ $20 \mathrm{~cm}$ thin layer chromatography (TLC) plate along with aflatoxin standard of known concentration. The spotted TLC 
plate was developed in an equilibrated tank containing chloroform:acetone $(9: 1 \mathrm{v} / \mathrm{v})$. The developed TLC plate was air-dried at ambient temperature $\left(28 \pm 2{ }^{\circ} \mathrm{C}\right)$ and aflatoxin were detected under UV light at wavelength of $360 \mathrm{~nm}$. A colour change from blue to yellow upon exposure to aqueous sulphuric acid (50:50 v/v) confirmed the presence of aflatoxin $\mathrm{B}_{1}[11]$.

\subsection{Quantification of Aflatoxin in the Ogi Slurry}

Preparative plates of $0.5 \mu \mathrm{m}$ thickness were employed for the quantification. Zero point eight milliliter $(0.8 \mathrm{ml})$ of stored extracts was applied to the TLC plate for band formation on the chromatograph. The preparative TLC plates were developed in an equilibrated tank in an aflatoxin extraction. The solute rise to the solvent front up to about $3 / 4$ of the total length of the plate, the plate was taken out of the tank and examined under UV light. Once the area containing the toxin of interest was located after UV light examination, it was scrapped off, washed with chloroform and filtered using Whatman No. 1 filter paper. The extract was evaporated to dryness over a hot water bath and reconstituted with $3 \mathrm{ml}$ chloroform. The $3 \mathrm{ml}$ reconstituted solution and aflatoxin standard of $20 \mu \mathrm{g} / \mathrm{ml}$ concentration was used to read absorbance on an ultraviolet Spectrophotometer (Cecil instrument CE505) at a wavelength of $360 \mathrm{~nm}$.

\subsection{Data Analysis}

The data obtained from this study was subjected to analysis of variance (ANOVA) using SPSS Version 16, Window 8 and the mean were compared using Duncan Multiple Range Test.

\section{Results}

Table 1 shows the total colony counts of toxigenic strain of Aspergillus flavus after initial inoculation of the samples. The fungal counts decreased as the inoculation time progresses. The high fungal counts $37.33 \mathrm{sfu} / \mathrm{ml}$ was recorded at the day 1 of the initial inoculation of sample fermented in ethanol and water, followed by $29.00 \mathrm{sfu} / \mathrm{ml}$ at day 2 while the least count $13.00 \mathrm{sfu} / \mathrm{ml}$ was obtained at day 4 of the initial inoculation with time. The fungal count of the sample fermented in ordinary water was recorded highest 27.00 $\mathrm{sfu} / \mathrm{ml}$ at day 1 and the least counts $15.00 \mathrm{sfu} / \mathrm{ml}$ was recorded at day 4 with initial inoculation time. The Sample fermented in sodium hypochlorite $\left(\mathrm{H}_{2} \mathrm{PO}_{4}\right)$ show no fungal growth throughout the initial inoculation with time.

Table 1. Total colony count of Aspergillus flavus after initial inoculation of the samples.

\begin{tabular}{|c|c|c|c|c|}
\hline Samples & 0 hour & 24 hours & 48 hours & 72 hours \\
\hline $\mathrm{AH}(\mathrm{sfu} / \mathrm{ml})$ & $27.00^{\mathrm{a}} \pm 5.03$ & $17.33^{b} \pm 4.49$ & $18.00^{b} \pm 4.04$ & $15.00^{b} \pm 5.77$ \\
\hline AHE (sfu/ml) & $37.33^{a} \pm 10.68$ & $29.00^{\mathrm{a}} \pm 8.51$ & $27.80^{\mathrm{a}} \pm 8.51$ & $13.00^{b} \pm 2.52$ \\
\hline AHP (sfu/ml) & $0.00^{\mathrm{c}} \pm 0.00$ & $0.00^{\mathrm{c}} \pm 0.00$ & $0.00^{\mathrm{c}} \pm 0.00$ & $0.00^{c} \pm 0.00$ \\
\hline
\end{tabular}

Mean values in the same column with the same superscript of alphabet are significantly different at $\mathrm{p} \leq 0.05$.

Key: $\mathrm{AH}=$ Sample fermented in ordinary water, $\mathrm{AHE}=$ Sample fermented in ethanol and water, $\mathrm{AHP}=\mathrm{Sample}$ fermented in sodium hypochlorite $\left(\mathrm{H}_{2} \mathrm{PO}\right)_{4}$.

Table 2. Total colony count of Aspergillus flavus after fermented samples had been milled and processed differently.

\begin{tabular}{ll}
\hline Samples & No of colonies $(\mathbf{c f u} / \mathbf{g})$ \\
\hline ODT & $14.50^{\mathrm{a}} \pm 4.28$ \\
SDT & $0.00^{\mathrm{b}} \pm 0.00$ \\
ABT & $0.00^{\mathrm{b}} \pm 0.00$ \\
\hline
\end{tabular}

Mean values in the same column with the same superscript of alphabet are significantly different at $\mathrm{p} \leq 0.05$.

Key: ODT $=$ Oven dry treatment, $\mathrm{SDT}=$ Sun-dry treatment, $\mathrm{ABT}=$ Alkaline boiling

Table 2 shows the total colony count of Aspergillus flavus after fermented samples had been milled and processed differently. The sample subjected to oven dry treatment had the highest colony count $15.50 \mathrm{sfu} / \mathrm{g}$ while the samples subjected to sundry and alkaline boiling showed no colony growth of $0.00 \mathrm{sfu} / \mathrm{g}$.

Table 3 shows the total spore count after initial inoculation of Aspergillus flavus into the samples. The spore count decreased as the fermentation time increases. The sample fermented in ethanol and water recorded the highest spore count when compared to other samples treated. The highest spore count $3.98 \mathrm{sfu} / \mathrm{ml}$ was recorded from AHE, at day 1, followed by $3.68 \mathrm{sfu} / \mathrm{ml}$ at day 2 while the least spore counts was recorded at day 4 of the fermentation. The highest spore count recorded from sample fermented in ordinary water were not significantly different at day 1 to day 3 while the least spore count $2.45 \mathrm{sfu} / \mathrm{ml}$ was obtained at day 4 . The samples fermented in water containing sodium hypochlorite $(1: 20 \mathrm{v} / \mathrm{v})$ show no growth of Aspergillus flavus throughput the fermentation period (Table 3 ).

Table 3. Total spore count after initial inoculation of Aspergillus flavus into the samples.

\begin{tabular}{llll}
\hline Samples & 0 hour & 24 hours & 48 hours \\
\hline AH $(\mathrm{sfu} / \mathrm{ml})$ & $3.82^{\mathrm{a}} \pm 0.44$ & $3.33^{\mathrm{a}} \pm 0.19$ & $3.27^{\mathrm{a}} \pm 0.21$ \\
$\mathrm{AHE}(\mathrm{sfu} / \mathrm{ml})$ & $3.98^{\mathrm{a}} \pm 0.34$ & $3.68^{\mathrm{a}} \pm 0.27$ & $3.50^{\mathrm{a}} \pm 0.23$ \\
AHP $(\mathrm{sfu} / \mathrm{ml})$ & $0.00^{\mathrm{c}} \pm 0.00$ & $0.00^{\mathrm{c}} \pm 0.00$ & $0.00^{\mathrm{c}} \pm 0.00$ \\
\hline
\end{tabular}

Mean values in the same column with the same superscript of alphabet are not significantly different at $\mathrm{P} \leq 0.05$.

$\mathrm{Key}: \mathrm{AH}=$ Sample fermented in ordinary water, $\mathrm{AHE}=$ Sample fermented in ethanol and water, $\mathrm{AHP}=\mathrm{Sample}$ fermented in water and sodium hypochlorite $\left(\mathrm{H}_{2} \mathrm{PO}_{4}\right)$. 
Table 4 shows the level of aflatoxin (ppb) in processed millet ogi slurry. For all the samples, $0.00 \mathrm{ppb}$ aflatoxin level was recorded for $\mathrm{AFG}_{1} \mu \mathrm{g} / \mathrm{kg}$ and $\mathrm{AFG}_{2} \mu \mathrm{g} / \mathrm{kg}$. The samples fermented in water and ethanol + sun drying showed the highest aflatoxin level 0.03 for $\mathrm{AFB}_{2}$, followed by samples fermented in ordinary water and samples fermented in water and ethanol + sun drying for $\mathrm{AFB}_{1}$. The aflatoxin level 0.01 $\mu \mathrm{g} / \mathrm{kg}$ was recorded for samples fermented in water and ethanol and samples fermented in water and ethanol + alkaline boiling for $\mathrm{AFB}_{1}$ and $\mathrm{AFB}_{2}$.

Table 4. Level of Aflatoxin (ppb) in processed millet ogi slurry.

\begin{tabular}{llll}
\hline Sample Code & $\mathbf{A F B}_{\mathbf{1}} \boldsymbol{\mu} \mathbf{g} / \mathbf{k g}$ & $\mathbf{A F B} \boldsymbol{\mu g} / \mathbf{k g}$ & $\mathbf{A F G} \mathbf{\mu g} / \mathbf{k g}$ \\
\hline 1 & $0.01^{\mathrm{a}} \pm 0.00$ & $0.01^{\mathrm{a}} \pm 0.00$ & $0.00^{\mathrm{c}} \pm 0.00$ \\
2 & $0.02^{\mathrm{a}} \pm 0.00$ & $0.01^{\mathrm{a}} \pm 0.00$ & $0.00^{\mathrm{c}} \pm 0.00$ \\
3 & $0.01^{\mathrm{a}} \pm 0.00$ & $0.01^{\mathrm{a}} \pm 0.00$ & $0.00^{\mathrm{c}} \pm 0.00$ \\
4 & $0.01^{\mathrm{a}} \pm 0.00$ & $0.00^{\mathrm{c}} \pm 0.00$ & $0.00^{\mathrm{c}} \pm 0.00$ \\
5 & $0.00^{\mathrm{c}} \pm 0.00$ & $0.00^{\mathrm{c}} \pm 0.00$ & $0.00^{\mathrm{c}} \pm 0.00$ \\
6 & $0.02^{\mathrm{b}} \pm 0.00$ & $0.03^{\mathrm{b}} \pm 0.04$ & 0.00 \\
7 & $0.00^{\mathrm{c}} \pm 0.00$ & $0.00^{\mathrm{c}} \pm 0.00$ & $0.01^{\mathrm{a}} \pm 0.00$ \\
8 & $0.00^{\mathrm{c}} \pm 0.00$ & $0.00^{\mathrm{c}} \pm 0.00$ & $0.00^{\mathrm{c}} \pm 0.00$ \\
\hline
\end{tabular}

Mean values in the same column with the same superscript of alphabet are not significantly different at $\mathrm{P} \leq 0.05$.

Key: $\mathrm{AFB}_{1}=$ Aflatoxin $\mathrm{B}_{1}, \mathrm{AFB}_{2}=$ Aflatoxin $\mathrm{B}_{2}, \mathrm{AFG}_{1}=$ AflatoxinG $\mathrm{G}_{1}, \mathrm{AFG}_{2}=$ Aflatoxin $\mathrm{G}_{2}, 1=$ Samples fermented in water and ethanol, $2=$ samples fermented in ordinary water, $3=$ sample $1+$ alkaline boiling, $4=$ sample $2+$ alkaline boiling, $5=$ sample $1+$ oven drying, $6=$ sample $1+$ sun drying, $7=$ sample $2+$ oven drying, $8=$ sample $2+$ sun drying.

\section{Discussion}

The result obtained from this study revealed the different processing techniques adopted reduced the major proportion of aflatoxin in the samples. The reduction in the aflatoxin level of ogi slurry treated with sunlight cause a significant decrease in both $\mathrm{AFB}_{1}$ and total aflatoxins content. The degree of aflatoxin reduction was found to be dependent on the duration of exposure to sunlight. This findings was in agreement with [12] who reported $75 \%$ significant $(\mathrm{p}<0.05)$ reduction in $\mathrm{AFB}_{1}$ of the aflatoxin-contaminated crude groundnut oil after solar irradiation treatment for 10 minutes. The solar radiation causes the slight increase in the colour of fatty acid [13]. The results also indicated that solar irradiation was not capable of completely destroying the aflatoxins in the millet and ogi samples. This could be due to the homogeneity in the particle size of the millet that would retain a larger proportion of aflatoxins thereby preventing penetration of solar irradiation to the whole sample. Penetration of radiation into aflatoxin recovered from groundnut oil has been reported [14]. The effect of sun drying on samples fermented in water and ethanol was found to be the least effective in degradation of aflatoxins, this could be due to some reactions between ethanol and aflatoxins in the sample that make them resistance to photodegradation.

Previous studies showed that chemical degradation of toxins with chlorine are less satisfactory bisulfate has low efficiency with the possibility of toxic epoxide formation [15]. However, since sodium hypochloride could effectively eliminate toxigenic strain of Aspergillus flavus in 0 hour, grain samples may be steeped in water containing sodium hypochloride $(20: 1 \mathrm{v} / \mathrm{v})$ for 30 minutes, drained before being steeped in fresh water for the fermentation process. Therefore, the possibility of an epoxide being formed over an extensive period will greatly reduce.

The aflatoxin level of the sample treated with alkaline boiling reduced significantly $(\mathrm{p}<0.05)$. Ramzi et al. [16] had reported a reduction in the aflatoxin levels from $127 \mu \mathrm{g} / \mathrm{kg}$ in raw maize to $68.6 \mu \mathrm{g} / \mathrm{kg}$ in tortillas subjected to alkaline cooking. The result obtained from this study fall with the permissible level of aflatoxin level of most cereals product.

The aflatoxin level of the sample treated with water and water containing ethanol appeared to have some effect in the removal of Aflatoxin B and $\mathrm{G}$ in the samples. The the of lactic acid bacteria on the growth of Aspergillus flavus has been reported [17]. [18] reported a decrease in aflatoxin content of most food products due to the presence of lactic acid bacteria which inhibit aflatoxin biosynthesis.

Results obtained by various authors are somewhat conflicting, since some of them report partial reduction in some mycotoxins while others note total reduction. From the findings, the mycotoxin levels of millet were relatively high, necessitating stronger processing conditions in terms of alkaline concentration and cooking time.

\section{Conclusion}

Different processing methods have shown the reduction, decontamination and removal of toxigenic strain of Aspergillus flavus that are found to vary in their efficacy in toxin removal from millet and ogi samples. 72 hours of fermentation was effective in reduction of aflatoxin level by almost $50 \%$. Photodegradation, oven drying and alkaline boiling were found to be effectively reduced or eliminate Aflatoxin $\mathrm{B}_{1}\left(\mathrm{AFB}_{1}\right), \mathrm{B}_{2}\left(\mathrm{AFB}_{2}\right), \mathrm{G}_{1}\left(\mathrm{AFG}_{1}\right)$ and $\mathrm{G}_{2}\left(\mathrm{AFG}_{2}\right)$. Sodium hypochlorite was effective at ratio 1:20 (v/v) in removal of toxigenic strain of Aspergillus flavus at 0 hour from the millet sample during fermentation.

\section{References}

[1] Sorenson, W. G., Jones, W., Slimpson, J. and Davison, J. I. (2004). Aflatoxin in respirable airborne peanut dust. Journal of Toxicology and Environmental Health, 14: 525-533. 
[2] Barnnett, J. W. and Klich, M. (2003). Mycotoxins. Clinical Microbiology, Reviewed 16: 497-516.

[3] Smith, A. P. (2005). Caffeine. In Lieberman H, Kanarek, R. and Prasad, C. (Edn). Nutritional neuroscience. CRC Press. pp. 335-359.

[4] Nafeesa, Q. H., Muhammad, N., Salma, K. and Najama, M. (2005). Prevalence of mycotoxins in poultry finished feed. Journal of Animal and Vetenary Advances, 4(2). 189-193.

[5] Williams, J. H., Philips, T. D., Jolly, P. E., Stiles, J. K., Jolly, C. M. and Aggariwal, D. (2000). Human aflatoxicoses in developing countries: a review of toxicology, exposure, potential health consequences and interventions. American Journal clinical and Nutrition, 80: 1106-22.

[6] Maryann, E. S. and Sophie, S. C. (2001). Elizabeth A. Bailey and John M. Essingmann: The chemistry and biology of aflatoxin $\mathrm{B}_{1}$. Carcinogenesis, 22(4): 535-545.

[7] Maitree, S. (2007). Prevention and control of mycotoxins in food grains. African Journal of Food Agriculture, Nutrition and Development, 12: 1-9.

[8] Bhumi N. R. and Chinnam R. R. (2007). Outbreaks of Aflatoxicoses in India. African Journal of Food Agriculture, Nutrition and Development 22: 1-15.

[9] Adams, R. M., Fleming, R. A. Chang, C. C., McCarl, B. A. and Rosenzweig, C. (1995). A reassessment of the economic effects of global climate change on U.S. Agriculture. Climatic Change, 30: 147-167.

[10] Adegoke, G. O., Iwahashi, H., Komatsu, Y., Obuchi K. and andIwahashi, Y. (2000). Inhibition of food spoilage yeasts and aflatoxigenic moulds by monoterpenes of the spice Aframomumdanielli. Flavour Fragrance Journal, 15: 147-150.
[11] Jeff-Agboola, Y. A. (2015). Influence of climate change on aflatoxin levels of some poultry feeds collected from feed mills in South-Western Nigeria. International Journal of Scientific and Engineering Research, 6(7): 1926-1947

[12] Schatzmayr, G., Zehner, F., Taubel, M., Binder, M and Klimitsch, A. (2006). Microbiologicals for deactivating mycotoxins.

[13] Speijers, G. J. A. and Speijers M. H. M. (2004). Combined toxic effects of mycotoxins. Toxicology Letter, 153: 91-98.

[14] Bhumi N. R. and Chinnam R. R. (2007). Outbreaks of Aflatoxicoses in India. African Journal of Food Agriculture, Nutrition and Development, 3: 1-15.

[15] Abrahamson, D., House, J. D., and Nyachoti, C. M. (2005). Reduction of deoxynivalenol in barley by treatment with aqueous sodium carbonate and heat. Mycopathologia, 160: 297-301.

[16] Ramzi, S. C., Vinay, K. and Tucker, C. (2009). Robbins Pathologic Bases of Disease Sixth Edition, pp. 889.

[17] Udoh, J. M., Cardwell, K. F., Ikotun, T. (2002). Storage structures and aflatoxin content of maize in five agroecological zones of Nigeria. Journal of Stored Production and Research, 36: 187-201.

[18] Groopman, J. D. and Kensler, W. (2006). Temporal patterns of aflatoxin-albumin adducts in hepatitis B surface antigenpositive and antigen residents of Daxin, Qidong County, People's Republic of China. Cancer Epidemiology Biomarkers and Prevention, 5: 253-261. 